\title{
A relação entre Estado e políticas públicas: uma análise teórica sobre o caso brasileiro
}

\author{
The relationship between State and public policies: a theoretical \\ analysis of the Brazilian case
}

\author{
Allan Gustavo Freire da Silva \\ Leonardo de Araújo e Mota \\ Carina Seixas Maia Dornelas \\ Alecksandra Vieira de Lacerda
}

\section{Resumo}

No Brasil, a relação existente entre o Estado, Governo e Políticas Públicas é complexa. Neste sentido, emerge a necessidade de uma ampliação da presença do Estado, o qual amparado no princípio do bemcomum, deve se fazer presente em diversas áreas, suprindo lacunas sociais. O objetivo deste trabalho é traçar uma linha elucidativa sobre as características do Estado, do Governo e do ciclo das Políticas Públicas no Brasil contemporâneo, destacando a interrelação deste conjunto institucional na gestão pública. Para tanto, buscou-se apresentar os procedimentos teórico-metodológicos que envolvem o ciclo das políticas públicas através de pesquisa bibliográfica. Concluiu-se que existiu melhor rendimento governamental após a reforma gerencial dos anos 1990, ao colocar em prática o ciclo das políticas aliadas à participação popular, além de estratégias responsivas, eficazes e eficientes para o alcance dos objetivos almejados.

\section{Palavras-chave}

Estado; Governo; Políticas Públicas; Gestáo Pública.

\begin{abstract}
In Brazil, the relationship between State, Government and Public Policies is complex. In this sense, emerges the need for expansion of state's presence by the principle of the common good, that must be reflected in several areas in order to reduce social gaps. The objective of this paper is to elucidate state's characteristics, Government and cycle of public policies in contemporary Brazil, highlighting the interrelatedness of this institutional set-up in public management. Therefore, we sought to present the theoretical and methodological procedures that involve the cycle of public policies through bibliographical research. We concluded that there was better government revenue after the management reform in the 1990's, that has put into practice the policy cycle allied to popular participation, and responsive, effective and efficient strategies to achieve the intended goals.
\end{abstract}

\section{Keywords}

State; Government; Public Policies; Public Administration. 
26 | Allan Gustavo da Silva, Leonardo Mota, Carina Dornelas e Alecksandra Lacerda

\section{Introdução}

A convivência social requer ferramentas que venham a proteger direitos e promover a harmoniosa convivência entre os indivíduos em uma coletividade, além do reconhecimento territorial nacional diante de outros povos. Nesse prisma o Estado se estrutura sob o fundamento de manter a coesão social, garantir a propriedade privada e outros direitos coletivos - que com o amadurecimento do Estado, surge a ideia e prática de um Estado voltado ao Bem-Estar-Social, o qual busca satisfazer a populaçáo através de políticas públicas focalizadas e universais - as quais buscam tratar com isonomia os iguais e os desiguais, na medida em que se desigualam, conforme a formação histórica de cada sociedade. Segundo Cardoso (2010):

O enfoque latino-americano de políticas dá a ênfase indispensável às políticas universais, como educação e saúde, sem deixar de dirigir esforços para beneficiar os segmentos mais vulneráveis da população, sobretudo quando eles são numerosos. $\mathrm{Na}$ tradição social-democrática europeia o bem-estar foi promovido por políticas públicas que reforçaram o acesso à educação, à saúde e à previdência social (CARDOSO, 2010, p. 195).

O Estado se apresenta como uma unidade básica social com território definido e com uma nação constituída pela coletividade que habita determinada localidade, genericamente entendida como um povo. Atualmente, a principal forma de organização política dá-se por meio do Estado Moderno. A sociedade civil, legitimadora e financiadora do Estado, o credencia a administrar as questôes mais importantes do convívio social e, em nome da ordem, concede também a ele o direito de ser a única instituição a poder fazer o uso legítimo da força física conforme destacou Max Weber (ALBINO, 2016).

Por Governo, entende-se o conjunto de indivíduos que ocupam, na cúpula do Estado, posições de decisão administrativa e política e que orientam os rumos da sociedade (RODRIGUES, 2010). Ao participar do governo, os indivíduos participam do ciclo das políticas públicas - definição da agenda política, elaboração, implementação e avaliaçáo. Sendo assim, escolhem dentre diversas alternativas quais serão as políticas e as açóes a serem praticadas pelo governo para o alcance de objetivos preestabelecidos. Tratando-se de um governo democrático, as preferências e interesses passam a ser constantemente negociadas, e envolve os interesses de diversos atores que compóem o aparato estatal.

As políticas públicas podem ser entendidas como a maneira pela qual o Estado atua para amenizar os conflitos e desigualdades sociais. Elas são desenhadas a 
partir do relacionamento e dos interesses existentes entre várias camadas da sociedade. Nesse processo, os atores políticos possuem importante participação para a focalizaçáo e destinação de recursos públicos para determinada política pública. Além disso, é importante salientar que a implementação das políticas públicas nas sociedades capitalistas também está sujeita a interferência de cenários macroeconômicos de crise ou estabilidade (MOTA, 2014).

Durante o ciclo das políticas públicas, atores públicos, compreendidos como os gestores públicos, juízes, burocratas, políticos e outras instituições do Governo, referem-se aos que de fato podem decidir sobre o encaminhamento das políticas. Atores privados, por exemplo, consumidores, empresários, trabalhadores, corporaçôes, centrais sindicais, mídia, entidades do terceiro setor, dentre outros, são aqueles que têm poder para direcionar a formatação das políticas e exercer influências sobre os agentes públicos.

Sendo assim, o objetivo deste artigo é apresentar partes estruturais do nosso ordenamento estatal, salientando a interaçáo existente entre o conceito e a finalidade do Estado, a importância das atribuiçôes do Governo no processo de administração política e as nuances que envolvem a ação estatal, mediante as relevantes disputas de interesses que abarcam o ciclo das políticas públicas e que influenciam o processo final das policies.

Busca-se com este artigo descrever as características do Estado, do Governo e do ciclo das Políticas Públicas, destacando a interrelação deste conjunto institucional na gestão pública. Assim como, correlacionar o papel institucional do Estado e do Governo no processo de viabilização de políticas públicas, analisando em qual medida o Estado institucionaliza processos que busquem gerar canais de comunicação entre a sociedade e os processos inerentes às políticas públicas. Para tanto, esta pesquisa utilizou, como respaldo teórico, autores como Carlos Alberto Almeida, Paulo Bonavides, Jean-Jacques Rosseau, Marta Rodrigues, Celina Souza, Klaus Frey, dentre outros.

Para o desenvolvimento do artigo, foi realizada uma sucinta exposição acerca das atribuiçôes institucionais do Estado e do Governo, buscando-se avaliar sua relação com os processos que envolvem o ciclo das políticas públicas. Tal análise parte da identificação de características legais inerentes ao Estado, ao Governo e sua capacidade de promover políticas públicas de acordo com as regras institucionais previamente estabelecidas e as condiçôes sócio-históricas de cada época. A partir das referidas observaçôes sobre as características de cada ente supracitado, intentou-se 
28 Allan Gustavo da Silva, Leonardo Mota, Carina Dornelas e Alecksandra Lacerda

compreender em qual medida estas instituiçóes apresentam discricionariedade, prevista legalmente, para fomentar a participaçáo popular no processo de composiçáo das políticas públicas.

\section{Características do Estado, do governo e das politicas públicas}

\section{O Estado}

A composição do conjunto de regras que forma a noção de Estado é estabelecida pela aglutinação de sociedades, as quais, situadas em determinado território, visando à proteção da propriedade privada e a regulação de atribuiçóes gerais e coletivas, se submetem a regras e acordos comuns. Para Del Vecchio (1958 apud BONAVIDES, 2000) o termo sociedade envolve o conjunto de relaçóes mediante as quais os indivíduos vivem e atuam solidariamente capaz de formar uma entidade nova e superior. Não se detendo sobre teorias organicistas - que se concentram no valor da sociedade - ou conforme teorias mecanicistas - aqueles que enxergam na sociedade apenas a mera soma de partes -, partindo da premissa de que o homem é um ser social, o Estado passa a desenvolver funçóes distintas e necessárias à manutenção da vida da coletividade.

Rousseau (2003) afirmava que a liberdade natural do homem, seu bem-estar e sua segurança seriam preservados através do contrato social. Rousseau foi um importante ator para se pensar na figura de um Estado incumbido de organizar a sociedade civil. A ideia de um contrato social surge para proteger a propriedade privada, a qual segundo Rousseau seria a origem das desigualdades entre os homens, a ponto de envolverem-se em usurpaçóes de uns contra outros. Sendo assim, o contrato social, que muito influenciou a criação do Estado como conhecemos, faz com que o povo seja, ao mesmo tempo, parte ativa e passiva nessa relação. Constitui-se em um acordo legítimo, o qual a vontade individual é subjugada em prol da vontade de todos.

Desta forma, considerando a faixa temporal, a sociedade surge primeiro e o Estado depois. O conjunto de regras que forma o Estado caracteriza-se por um contrato social, conforme expresso por Rousseau. Neste sentido, Bonavides (2000) assevera que: 


\begin{abstract}
A burguesia triunfante abraça-se acariciadora a esse conceito que faz do Estado a ordem jurídica, o corpo normativo, a máquina do poder político, exterior à Sociedade, compreendida esta como esfera mais dilatada, de substrato materialmente econômico, onde os indivíduos dinamizam sua ação e expandem seu trabalho (BONAVIDES, 2000, p. 70).
\end{abstract}

Destarte, o Estado passa a ser o conjunto de regras que visa proteger e atender a vontade geral. Composto pela heterogenia entre o ordenamento jurídico e suas normas, o Estado passa a ser dotado de capacidade decisiva, possuindo o poder sobre o uso coercitivo da força. Nessa macro instituiçáo denominada Estado, concentra-se a soma de interesses e claros poderes, os quais, em uma sociedade democrática, viabilizarão sua auto-regulação, os freios e os contrapesos - check and balances.

No tocante à moderna utilização do termo "Estado", seu emprego pode ser associado e remonta-se à obra de Maquiavel, intitulada "O Príncipe", na qual ele relaciona o conceito de Estado com o império e autoridade sobre os homens. Há, porém, conceituaçôes filosóficas e jurídicas a respeito do termo Estado, podendo receber entendimentos que fazem referência à moral e à ética, ou como a uma série de leis e regras às quais os homens se submetem.

Del Vecchio (1958 apud BONAVIDES, 2000) faz uma separação conceitual entre Estado e sociedade ao caracterizar Estado como o laço jurídico ou político, e sociedade como a pluralidade de laços. Desta assertiva, infere-se, dentre outras possíveis interpretaçôes, a dinamicidade de interesses individuais que constituem a formação do Estado, as lutas de classes, os movimentos sociais, as batalhas fiscais e as disputas pelo poder político.

A federação brasileira possui descentralização política e no que tange a organização político-administrativa do Brasil, a União, os Estados, o Distrito Federal e os Municípios são caracterizados como entidades autônomas - autonomia que garante equilíbrio. Nesse sentido, sendo a União a soma de estados e municípios inseridos neste arcabouço federativo, a garantia da estabilidade institucional é promovida por meio da Constituição Federal brasileira de 1988, a qual visa garantir a distribuição de competências e demonstração de coesão entre todos os entes federados, conforme expressa o princípio da indissolubilidade do vínculo federativo, registrado no artigo $1^{\circ} \mathrm{da}$ CF de 1988 (BRASIL, 1988)

Tratando-se do Brasil, e diante da constitucional divisão de responsabilidades entre as instituiçóes e da influência exercida pela sociedade - agente financiador e 
usuário dos bens e serviços públicos - no Estado, a obra intitulada "A cabeça do brasileiro" de Almeida (2007) indica que o nível de escolaridade é um fator determinante para a absorção de noçóes de democracia e igualdade. No entanto, apesar da presença de problemas sociais que retardam a existência de comportamentos democráticos, fundamentados a partir do aumento do nível de escolaridade dos brasileiros, observa-se que o sentimento paciente de Estado provedor é ainda complementado pela alta carga tributária do país, acentuando e intensificando o discurso de que "para os brasileiros, o Estado deve predominar na justiça, na previdência social, na saúde, na educação, no saneamento básico, no fornecimento de água, nas estradas e rodovias, no recolhimento de lixo, na produção de energia elétrica e nos bancos" (ALMEIDA, 2007, p. 178).

Tal compreensão sobre o papel do Estado na sociedade reforça as características de um Estado protetor, paternalista, o qual muito é demandado pela sociedade para satisfazer e suprir lacunas institucionais, sociais e organizacionais provocadas desde a formação histórica do país. Assim, sob a égide legítima da sociedade, o Estado desenvolve seus processos de manifestaçáo de poder. A democracia, o direito ao voto, à proteção da propriedade, dentre outras caraterísticas, faz com que esse contrato social entre a sociedade e a instituiçâo Estado, transformese em benefício da coletividade e do bem-comum, ao decidir sobre diversas áreas da vida dos cidadãos.

O funcionamento da máquina pública de forma eficaz e eficiente envolve a análise da governança - termo que para Pereira (2012) traduz-se na capacidade que os governos têm de elaborar e implementar políticas públicas. $\mathrm{O}$ alcance de altos níveis de desempenho da máquina do Estado também implica na administração dos mecanismos que constituem a policy arena - expressão que Frey (2000) conceitua relacionando-se aos processos de conflito e de consenso dentro das diversas áreas de política. A necessidade de controle dos conflitos de interesses entre os diversos atores presentes no ciclo das políticas públicas apresenta-se como um elevado desafio ao sucesso das políticas e a viabilização da promoção do Estado de bem-estar social, fundamentado, portanto, na geração de accountability (transparência na utilização dos recursos públicos) e nos princípios da eficiência e da eficácia na formulaçáo, implementação, avaliação e continuidade das políticas públicas bem sucedidas, às quais o Estado necessita. 


\section{O Governo}

O governo configura-se como a instância máxima de administração executiva, cuja atribuiçấo principal é direcionar políticas públicas e regular a sociedade politicamente. Nesse sentido, as políticas públicas compóem a forma pela qual o governo executa suas açôes. Rodrigues (2010) evidencia que:

Políticas públicas são ações de Governo, portanto, são revestidas da autoridade soberana do poder público. Dispóem sobre "o que fazer" (açôes), "aonde chegar" (metas ou objetivos relacionados ao estado de coisas que se pretende alterar) e "como fazer" (estratégias de ação) (RODRIGUES, 2010, p. 53).

A noção de Welfare State - Estado do Bem-Estar-Social - atribui ao Estado responsabilidades sociais, devendo este, garantir padrôes mínimos na área da saúde, educação, renda, habitação e seguridade social, dentre outras proteçôes, a todos os cidadãos. Trata-se, portanto, de um estado provedor, o qual direciona governos a traçarem políticas públicas que fortaleçam e atendam às características demandas pela população.

Apesar da clara incidência de Estados provedores em países desenvolvidos, para a avaliação de políticas públicas, existe a necessidade de resgate do papel do Estado. Os autores Seibel e Gelinski (2012) enfatizam que o resgate do papel ativo do Estado presente nos sistemas de Bem-Estar-Social, é o elemento de base daqueles que propóem avaliar as políticas públicas incluindo além das questôes fiscais, os agentes envolvidos.

Para a consecução dos objetivos governamentais, os governos devem possuir habilidades que se expressam na forma de governança e governabilidade. Rodrigues (2010) esclarece que a governança, pode ser entendida como a capacidade financeira e administrativa para implantar políticas públicas. $\mathrm{O}$ termo governabilidade está ligado à legitimidade do governo no poder e da capacidade de conduzir as instituiçóes públicas para o alcance dos interesses do governo, perante a sociedade. Pode-se então afirmar que governo se configura como um conjunto de indivíduos que direcionam a sociedade, por aqueles estarem ocupando posiçóes institucionais com alto poder de decisão.

Vale salientar que as açóes do governo sempre estão fundamentadas no poder político, na barganha de interesses políticos, em estratégias partidárias e ideologias de diversos segmentos da sociedade. As disputas por áreas que venham a ser 
contempladas nas políticas de governo dinamizam o debate, reunindo grupos sociais, empresários dentre outras organizaçóes, e pressionando o governo para atender determinadas demandas. No caso brasileiro, mais especificamente nos governos FHC e Lula, Castelo (2013) salienta que:

\begin{abstract}
Os sociais-liberais brasileiros propóem medidas de cunho administrativo para aumentar a efetividade das políticas sociais: 1) focalização dos gastos sociais nos "mais pobres dos pobres", isto é, nos miseráveis; 2) avaliaçáo do impacto das políticas sociais; e 3) integração dos programas sociais em todos os níveis governamentais - federal, estadual e municipal - e do setor privado (CASTELO, 2013, p. 351-352).
\end{abstract}

Sendo assim, governos eficazes, têm poder político suficiente para tomar decisóes de acordo com suas preferências e interesses individuais, buscando por meio de acordos, manter alianças e coalizóes que favoreçam sua administração, às decisóes políticas, à realizaçáo e ao cumprimento dos objetivos governamentais programados e definidos em consonância com diretrizes e intençôes partidárias.

\title{
As politicas públicas e sua abrangência conceitual
}

A análise de políticas públicas intensifica-se no Brasil a partir de 1980, proveniente da dinâmica política e das transformaçóes que o país enfrentava, com reformas econômicas e políticas nas áreas de saúde, educação, previdência, saneamento, dentre outras. Buscava-se, portanto, entender quais eram as possibilidades e os óbices para a implantação de mudanças, constitucionalmente inscritas e dependentes de decisóes governamentais.

O termo Políticas Públicas pode ser expresso a partir da caracterização dada por Rodrigues (2010), ao afirmar é o processo em que diversos grupos, cujos interesses divergem, tomam decisóes coletivas que direcionam a sociedade. Sobre isso, Souza (2006, p. 25) expressa que "as políticas públicas repercutem na economia e nas sociedades, daí por que qualquer teoria da política pública precisa também explicar as inter-relaçôes entre Estado, política, economia e sociedade".

O processo de redemocratização pautada numa transição de Estado burocrático para uma reforma gerencial do Estado, que se iniciou em 1970 e que foi acentuada em 1980, impulsionou a necessidade de democratização do acesso a serviços e à participação política, estimulando a geração de muitos trabalhos científicos que passaram a analisar as políticas setoriais com o intuito de interpretá-las e de propor mudanças no desenho institucional vigente (PEREIRA, 1996). 
A descentralização das atribuiçóes do Estado se acentuou a partir da metade dos anos da década de 1990, período em que o país passava por uma crise de governabilidade, sendo esta ainda, incitada pelos processos de globalização, os quais passaram a exigir do Estado novos comportamentos para satisfazer as demandas sociais por meio da busca pela viabilizaçáo de bem-estar, segurança e justiça, fatores que compreendem o tripé para a promoção do bem-comum.

Vale destacar que, no regime democrático, as descentralizaçóes de poder e a dinâmica dos processos eleitorais nas democracias modernas devem caminhar no sentido de permitir, cada vez mais, a ampla participação, bem como proporcionar sólida organização política a fim de constituir cenários de disputas em que os atores, candidatos e eleitores, possam se movimentar no jogo político fazendo uso de cálculos de custo-benefício. Nesse sentido, visando analisar a interrelação entre as instituiçóes políticas, o processo político e os conteúdos de política, a policy analysis - análise de políticas - se relaciona com os processos de polity, politics e policy. Essas três dimensôes de políticas são fundamentais, para a elaboração bem-sucedida de uma política pública.

Segundo Frey (2000), para realizar a análise de políticas, é necessário entender a polity, que se refere à ordem do sistema político, delineada pelo sistema e à estrutura institucional do sistema político-administrativo; a politics, como sendo os processos políticos conflituosos e a policy, que são as políticas públicas no seu processo final, os resultados das regras e dos conflitos. Como exemplo dessa interrelação na policy analysis, a polity, que corresponde às formas de governo, ao sistema de governo e as formas do Estado, irá interferir na politics e na policy. A policy analysis deve levar em conta as perspectivas neoinstitucionalistas, pois, essa perspectiva não explica tudo por meio das instituiçôes, ao também considerar o comportamento dos diversos atores. Em situações nas quais os processos políticos são pouco consolidados, é difícil explicar os acontecimentos pelo fator institucional. Impóe-se como componente explicativo adicional o fator "estilo de comportamento político", que irá influenciar nas relações políticas.

Analisar o contexto dos atores e onde eles estáo inseridos, bem como a cultura política e o carisma do candidato na regiáo, são requisitos fundamentais para a aplicação de políticas em países em desenvolvimento. Assim sendo, a discussão sobre políticas públicas deve levar em conta o desenho institucional. No caso brasileiro, deve-se considerar o presidencialismo de coalizão - aliança política firmada entre o chefe do poder Executivo com partidos políticos eleitos, para cumprimento de 
34 | Allan Gustavo da Silva, Leonardo Mota, Carina Dornelas e Alecksandra Lacerda

mandato no poder Legislativo - e as negociaçóes entre os poderes Executivo e o Legislativo para produção legal.

Souza (2006) resume o termo política pública como o campo do conhecimento que busca, "colocar o governo em ação" e/ou avaliar essa ação. Tendo a possibilidade de propor mudanças durante a execução dessas açóes. Destarte, as políticas públicas podem ser estudadas tanto a partir da perspectiva da açáo do Governo - o que faz - quanto da inaçáo, o que o governo não faz. Partindo do conceito sobre democracia, a independência e equilíbrio entre os poderes, estão inseridos sob a égide da Constituiçâo de 1988, a qual em seu artigo $1^{\circ}$, parágrafo único, evidencia que "todo poder emana do povo" (BRASIL, 1988). Sendo assim, as políticas públicas, sobretudo, se definem menos pela racionalidade dos seus agentes institucionais e mais pela capacidade que a sociedade civil tem de influenciar as açóes governamentais.

Rodrigues (2010) salienta que a engenharia das políticas públicas requer duas avaliaçóes: uma análise sobre como as decisóes são tomadas e outra sobre o poder que o Governo possui para prevenir uma situação. Assim, as políticas públicas devem ser explicadas baseando-se em diversos enfoques, dada a multidisciplinaridade que envolve tal estudo. Neste sentido, Frey (2000, p. 226) destaca que "as tradicionais divisóes do ciclo político nas várias propostas na bibliografia se diferenciam apenas gradualmente. Comum a todas as propostas são as fases da formulação, da implementação e do controle dos impactos das políticas".

Desse modo, a sistematização das políticas públicas pode ser caracterizada pelas seguintes etapas: definição da agenda, formulação, implementação e avaliação do programa. De acordo com esse modelo, políticas públicas são estruturadas como um processo, o qual reúne um conjunto de atividades - etapas - visando o alcance de demandas. Na Figura 1, expóe-se como se dar a sequência de estágios que irão montar determinada policy. 
Figura 1 - Etapas da política pública

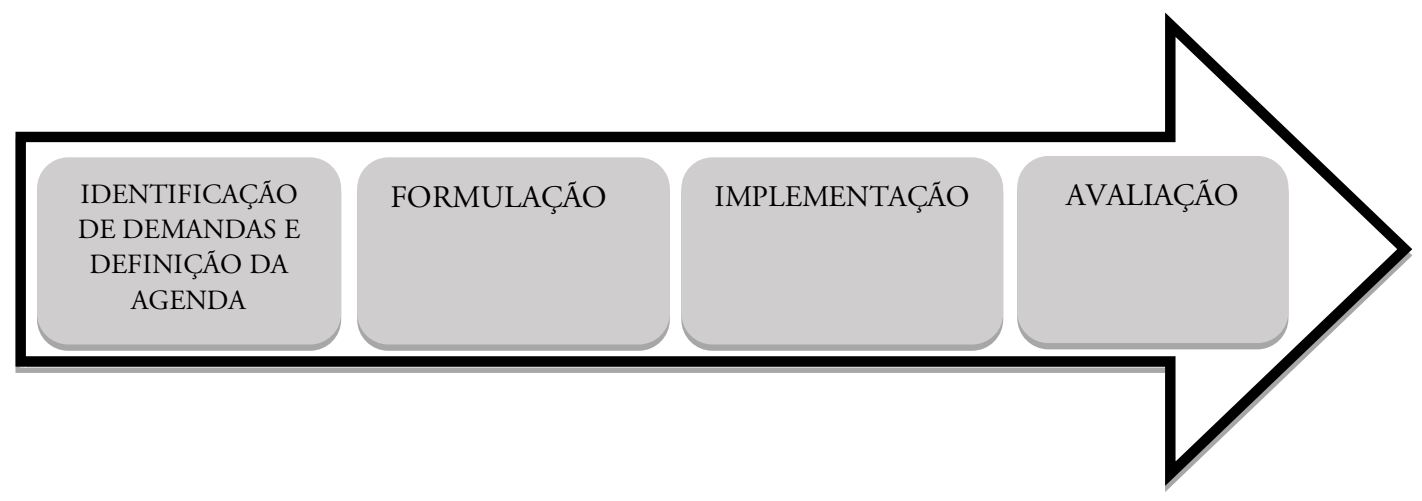

Fonte: Elaborado pelos autores, 2016.

$\mathrm{O}$ ato de elaboração das políticas públicas, compreende o esquema de organização de uma política pública através da identificação do problema, formação da agenda, formulação de alternativas, tomada de decisão, implementação e avaliação. As ponderaçóes referentes ao ciclo das políticas possuem grande utilidade prática, pois, são capazes de organizar ideias e apresentar com mais clareza os esboços e intençôes políticas aos administradores e outros envolvidos nas açóes que compôem o ciclo das políticas.

As etapas que envolvem o ciclo de políticas são moldadas de acordo com as intensas variaçóes e interpretaçóes dos policy makers e interferem, de forma decisiva, na tomada de decisão, as quais são influenciadas pelos interesses dos atores e pelas experiências técnicas e pessoais destes. $\mathrm{Na}$ fase do ciclo político, o processo de tomada de decisão pode se estruturar de três formas: a) a partir de problemas para formulação de soluçóes; b) por meio de ajustes dos problemas às soluções disponíveis, num processo simultâneo e comparativo entre os problemas existentes e as soluçóes propostas; c) mediante a disponibilidade de soluçóes que perseguem a detecção de problemas, já preferidos pelos tomadores de decisão e propensos a serem identificados pela opinião pública como questôes específicas que necessitam ser transformadas em política pública. 
Compreendendo o que comumente ficou conhecido como ciclo das políticas - Policy Cycle - na primeira etapa; identificação de demandas e definição da agenda, ocorre a identificação de um problema e possíveis soluções. Tal constatação pode acontecer, simplesmente, devido a necessidade de atuação governamental em algum nicho do setor público, o qual este tenha interesse em atuar ou naqueles em que, legalmente, seja da sua responsabilidade. Em seguida, diante do problema pelo qual o governo decidiu agir, estrutura-se o que Frey (2000) destaca em sua obra de questão política - Policy Issue, sendo caracterizado como uma questáo pública.

Para Rodrigues (2010, p. 50), "o governo deve agir instantaneamente, caso contrário, é preciso aguardar pela abertura de uma nova janela de oportunidade, que inclui, como sabemos, um longo processo". De acordo com as mobilizaçóes acerca de determinada temática, do interesse daqueles que mantém o poder decisório, de uma apresentaçáo clara sobre como o governo pode participar de determinada política pública e da disponibilidade de capital social, econômico e político, o governo toma a decisão sobre o que irá compor a agenda de políticas, em um definido momento.

Dentre os processos que estruturam o ciclo de políticas públicas, a identificação do problema, avalia se existe alguma discrepância entre a situação atual e uma possível situaçáo ideal, entendida como aquilo que se gostaria que fosse feito. A composição da agenda irá aglutinar todos os problemas relevantes para a solução da questão, no entanto, a sua formação é uma atividade dinâmica, onde problemas podem entrar e sair da agenda de acordo com critérios de oportunidade e conveniência na busca para a resoluçáo dos problemas. A atividade de formulaçáo de alternativas ocorre a partir da leitura dos problemas elencados na agenda e da combinação de possíveis soluções dos problemas críticos, nessa etapa; métodos, programas, estratégias e ações são realizadas visando à construção de alternativas para o alcance de objetivos instituídos durante a formulação das alternativas.

$\mathrm{Na}$ fase de formulação de políticas públicas é levantada em conta as discussōes acerca do conjunto de açóes pertinentes, as quais irão formar determinada política. Nessa fase, há a conversão das questóes presentes da agenda em política - desenhando a proposta e delimitando objetivos. Souza (2006) assevera que a formulaçáo de políticas públicas se constitui no estágio em que os governos democráticos executam seus propósitos, previamente expostos no período eleitoral e que irão modificar o contexto atual no qual estão inseridos.

Segundo Rodrigues (2010) para um determinado problema, a construção da solução implica na elaboração de um diagnóstico da situação em curso, além da identificação e desenvolvimento de alternativas. A formulação das políticas envolve a 
definição prévia da área em que serão extraídos os recursos financeiros para sua implementação, além do estabelecimento de coalizóes e negociaçôes a fim de preparar o cenário político e o ambiente econômico para a aceitação de uma política. A etapa de formulação constitui-se, portanto, em uma fase em que há a manutenção dos apoios políticos visando à aprovação e legitimação de uma política pública.

A fase da implementação contém a aplicação da política através do Governo. É a etapa em que se busca combinar e conciliar o tempo para a implantaçáo da política com os recursos financeiros e humanos disponíveis para seu cumprimento. Sua implantaçáo deve estar constantemente atendendo aos objetivos previamente estabelecidos. Ao final do processo, os resultados alcançados caracterizam o impacto da política implementada. A implementação da política pública, por sua vez, sucede a tomada de decisóes e antecede o processo de avaliação. É nesta fase onde os planejamentos, regras, rotinas, métodos e processos sociais são colocados em prática.

Fernandes, Castro e Maron (2013) argumentam que as políticas de forma geral, são desenvolvidas de maneira pouco articulada. Dessa forma, um dos grandes desafios é conhecer o local em que se pretende aplicar a política, harmonizar junto à equipe implementadora quais são os objetivos a serem alcançados e aparelhá-la com boa qualidade de recursos humanos/materiais. A capacidade decisória às adequaçóes e adaptaçóes dos atores locais às açóes públicas é fator preponderante que auxilia o bom resultado do processo de estabelecimento da política. A interação da política entre o governo e os diversos atores distribuídos entre o ciclo das políticas é essencial para um bom resultado de sua implementaçáo.

Lima e D’Ascenzi (2013) explicam que o sucesso da implementação de uma política pública decorre, sobretudo, da clareza dos objetivos, do estilo de implementaçáo a ser adotado e da capacidade de mediar conflitos de interesses. Assim, torna-se imprescindível que os implementadores compreendam perfeitamente a política e saibam exatamente o que se esperar dela, pois a conformação do processo de implementação recebe influência das características do plano, da estrutura e da dinâmica dos espaços organizacionais envolvidos - ideias, valores e interpretaçóes dos atores implementadores sobre a realidade.

O processo de avaliaçáo de uma política pública dá-se a partir do momento em que efeitos são gerados, possibilitando a análise de indicadores que demonstrem em que nível as metas foram atingidas. Faria (2005) ressalta que na década de 1960, em contexto de expansão sem precedentes, a avaliação é institucionalizada, tendo um desenho predominantemente top-down - de cima para baixo. Já na década de 1970, 
as características de análise top-down foram progressivamente revertidas, abrindo espaço para metodologias bottom-up - de baixo para cima. Compreendendo a análise de avaliação das políticas a partir da visão dos beneficiários da política e não apenas das interpretaçôes advindas dos idealizadores.

No que se refere à etapa de avaliação das políticas públicas, esta irá buscar mensurar os erros e acertos da política pública executada, bem como analisar critérios relacionados à economicidade, eficiência, eficácia e a equidade na distribuição dos benefícios entre os destinatários de uma política pública. Cunha (2006) explica que além do caráter de mensuração objetiva de resultados, a avaliação possui também aspectos qualitativos, constituindo-se em um julgamento sobre o valor das intervençôes governamentais envolvendo formuladores, avaliadores e beneficiários. A reforma gerencial do Estado, estimulada a partir dos anos de 1990, faz com haja uma série de medidas que fomentem o alcance de metas e a eficiência na gestão pública.

No entanto, em políticas sociais é mais fácil existir o envolvimento da populaçáo nos processos que compreendem o ciclo das políticas públicas. Já nas políticas econômicas e fiscais, a população mantém-se como expectadora do processo, uma vez que a execução de tais políticas faz parte do perfil administrativo adotado pelo governo e da interpretação do gestor público. Mesmo considerando os limites governamentais impostos à participação popular, Cunha (2006) salienta a existência da modalidade de avaliação participativa, a qual pode ser utilizada principalmente para pequenos projetos e prevê a participação dos beneficiários nas açóes de planejamento, na programação, execução e avaliaçáo por parte deles. Existe um crescente interesse dos governos nos estudos de avaliação, que está relacionado às questóes de efetividade, eficiência, accountability e desempenho da gestão pública, os quais funcionam como ferramentas na aplicação de recursos e no desenvolvimento das políticas públicas. Assim, a participaçáo popular nos processos de elaboração e avaliação de políticas passa a ser fundamental, tendo uma composição democrática e legitimadora nos processos decisórios do governo.

Merece destaque ainda que diante da análise feita a partir dos estudos de Souza e Secchi (2015), os quais observam que após o processo de avaliação, ainda pode compor o ciclo das políticas públicas a etapa de extinção de políticas. A extinção da política pública pode ocorrer em três situaçôes: quando sanados os problemas que originaram a política, momento em que a política alcançou o objetivo geral; quando o arcabouço legal que embasavam a política é identificado como ineficaz; ou quando o problema não é mais tido pelos atores ou pela opiniáo pública como prioridade, 
deixando de fazer parte da agenda de intervençôes necessárias do Estado, através de políticas públicas.

O processo de extinção de uma política pública envolve diferentes interesses sociais, que em sua maioria são marcados por conflitos. Políticas do tipo redistributiva e distributivas são difíceis de serem extintas, dados os benefícios proporcionados a um grupo específico ou a pequenos grupos organizados, que diante da coletividade desarticulada, conseguem de forma eficaz lutar pela defesa da continuidade de determinada política. As políticas regulatórias e constitutivas, por sua vez, esbarram na inércia do sistema institucional e no desinteresse dos atores políticos capazes de reprogramar a máquina estatal.

\section{Conclusão}

A delimitação constitucional de 1988 concedeu definidas atribuições ao Estado e ao governo no que se refere ao processo de formulaçáo e viabilização de políticas públicas. Os critérios adotados para o ciclo de políticas funcionam como uma eficiente ferramenta capaz de auxiliar os gestores públicos a instituírem objetivos e alcançarem metas.

A proposta de Welfare State - Estado do Bem-Estar-Social - passa a exigir do Estado participação ainda maior no que se refere às questóes que envolvem a coletividade e o bem-comum. Desse modo, torna-se ainda mais comum, políticas públicas que enveredam por essa temática e que abarquem o maior número de áreas sociais.

A participação popular nos processos que envolvem a governança e governabilidade, a implantação de políticas públicas e a legitimação de governos no poder, passa a ser prática amplamente difundida nas mais diversas esferas do governo brasileiro. Tais medidas passam a ser algumas das açôes governamentais que buscam fazer com que haja redução dos conflitos na elaboraçáo das políticas, ao utilizar-se da participação social nos processos de decisão que envolvem o poder Legislativo e o poder Executivo.

Dada a escassez de recursos públicos e a nova proposta inserida pela reforma gerencial que se intensifica a partir de 1990 no Brasil, o ciclo das políticas públicas, assume posição central, para a condução de projetos e programas governamentais. As fases de definição, elaboração e aplicação das políticas públicas, passam a ser objetivo de avaliação do governo, as quais funcionam como um termômetro para a aprovação social, diante da transparência, eficiência e eficácia de governos. 
$\mathrm{Na}$ atual fase do governo - dentre as diversas esferas estatais - a escassez de recursos públicos e a necessidade de cumprimento dos princípios: de transparência de seus atos, de eficiência - fazer mais com menos -, e da eficácia - alcançar as metas e os objetivos para os quais a política pública foi criada - faz com que aumentem as preocupaçóes governamentais e os cuidados acerca dos procedimentos que envolvem o planejamento de uma política pública. Tais condições, estimulam governos e gestores a terem minucioso conhecimento sobre a área de atuação e influências das policies, os impactos buscados a partir de determinada política, além de análises atinentes à plena capacidade da equipe envolvida, da adoção de metodologias exequíveis e da participação dos beneficiários nos processos de identificação de demandas, formulação, implementação e avaliação das políticas públicas.

Allan Gustavo Freire da Silva é Mestre em Desenvolvimento Regional pela Universidade Estadual da Paraíba (UEPB) e Professor da Universidade Federal de Campina Grande (UFCG). E-mail: allangfs@hotmail.com.

Leonardo de Araújo e Mota é Doutor em Sociologia pela Universidade Federal do Ceará (UFC) e Professor da Universidade Estadual da Paraíba (UEPB). E-mail: la-mota@uol.com.br.

Carina Seixas Maia Dornelas é Doutora em Agronomia pela UFCG e Professora da UFCG. E-mail: cacasmd@yahoo.com.br

Alecksandra Vieira de Lacerda é Doutora em Ecologia e Recursos Naturais pela Universidade Federal de São Carlos (UFSCAR) e Professora da UFCG.E-mail: alecvieira@yahoo.com.br.

\section{Referências}

ALBINO, Luciano. 10 liçôes sobre Max Weber. Petrópolis, RJ: Vozes, 2016. (Coleção 10 Liçôes).

ALMEIDA, Alberto Carlos. A cabeça do brasileiro. Rio de Janeiro: Record, 2007.

BONAVIDES, Paulo. Ciência Política. 10. ed. São Paulo: Malheiros, 2000.

BRASIL. Constituição. Constituição da República Federativa do Brasil: promulgada em 5 de outubro de 1988. 4. ed. São Paulo: Saraiva, 1990.

CARDOSO, Fernando Henrique. Xadrez internacional e social-democracia. São Paulo: Paz e Terra, 2010. 
CASTELO, Rodrigo. O social-liberalismo: auge a crise da supremacia burguesa na era neoliberal. São Paulo: Expressão Popular, 2013.

CUNHA, Carla Giane Soares da. Avaliação de Políticas Públicas e Programas Governamentais: tendências recentes e experiências no Brasil. In: The Theory and Operation of a Modern National Economy. Washington: George Washington University, 2006.

DEL VECCHIO, Giorgio. Lezioni di Filosofia del Diritto. 10. ed. Milano, 1958.

FARIA, Carlos Aurélio Pimenta de. A política da avaliação de políticas públicas. Revista Brasileira de Ciências Sociais, v. 20, n. 59, p. 97-169, 2005.

FERNANDES, Ana Tereza; CASTRO, Camila; MARON, Juliana. Desafios para implementação de políticas públicas: intersetorialidade e regionalização. VI Congresso CONSAD de Gestão Pública, $2013 . \quad$ Disponível em: <http://www.escoladegoverno.pr.gov.br/arquivos/File/2013/V_CONSAD/VI_CONSAD/025.pdf>. Acesso em: 10 mai. 2016.

FREY, Klaus. Políticas públicas: um debate conceitual e reflexóes referentes à prática da análise de políticas públicas no brasil. Planejamento e Políticas Públicas, n. 21. p. 211-260, jun. 2000. Disponível em: <http:/www.ipea.gov.br/ppp/index.php/PPP/article/viewFile/89/158>. Acesso em: 05 fev. 2016.

LIMA, Luciana Leite; D'ASCENZI, Luciano. Implementação de políticas públicas: perspectivas analíticas. Revista de Sociologia e Política, v. 21, n. 48, p. 101-110, dez. 2013. Disponível em: <http://www.scielo.br/pdf/rsocp/v21 n48/a06v21n48.pdf>. Acesso em: 09 mar. 2016.

MOTA, Leonardo de Araújo (Org.). Capitalismo contemporâneo: olhares multidisciplinares. Campina Grande: Eduepb, 2014.

PEREIRA, Luiz Carlos Bresser. Da administração pública burocrática à gerencial. Revista do Serviço Público, n. 47, p. 1-28, jan./abr. 1996. Disponível em: <http://www.bresserpereira.org.br/papers/1996/95.AdmPublicaBurocraticaAGerencial.pdf>. Acesso em: 30 fev. 2016.

PEREIRA, José Matias. Manual de gestão pública contemporânea. 4. ed. São Paulo: Atlas, 2012.

RODRIGUES, Marta Maria Assumpção. Políticas Públicas. São Paulo: Publifolha, 2010.

ROSSEAU, Jean-Jacques. O contrato social. 3. ed. São Paulo: Martins Fontes, 2003.

SEIBEL, Erni José; GELINSKI, Carmen Rosario Ortiz Gutierrez. Concepção do Estado e Escolha da Metodologia de Avaliação de Políticas Públicas. Cad. de Pesq. Interdisc. Em Ci-s. Hum-s., Florianópolis, v. 13, n. 102, p. 119-134, jan/jul 2012. Disponível em: <https://periodicos.ufsc.br/index.php/cadernosdepesquisa/article/view/24215>.

Acesso em: 05 mar. 2016.

SOUZA, Celina. Políticas Públicas: uma revisão de literatura. Sociologias, Porto Alegre, v. 8, n. 16, p. 20-45, jul./dez. 2006.

SOUZA, Yalle Hugo de; SECCHI, Leonardo. Extinção de Políticas Públicas Síntese Teórica sobre a Fase Esquecida do Policy Cycle. Cadernos Gestão Pública e Cidadania, São Paulo, v. 20, n. 66, p. 7593, Jan./Jun. 2015. Disponível em: <http://bibliotecadigital.fgv.br/ojs/index.php/cgpc/article/viewFile/39619/52574>. Acesso em: 25 mai. 2016. 
42 | Allan Gustavo da Silva, Leonardo Mota, Carina Dornelas e Alecksandra Lacerda

Texto recebido em 26 de março de 2017. Aprovado em 28 de março de 2017. 